\title{
(dis)Ability and Music Education: Paralympian Patrick Anderson and the Experience of Disability in Music
}

\author{
Adam Patrick Bell \\ University of Calgary, Canada
}

What does it mean to experience disability in music? Based on interviews with Patrick Anderson-arguably the greatest wheelchair basketball player of all time-this article presents insights into the complexities of the experience of disability in sports and music. Contrasted with music education's tendency to adhere to a medicalized model of disability, Anderson's nuanced views on disability in different contexts serves as an accessible point of entry to literature in the field of Disability Studies. Using Anderson's anecdotal experiences of disability in sports and music as catalysts, key concepts in Disability Studies are discussed including the medical and social models of disability, conventions of disability terminology, disability identity, and the relevance of Lubet's (2010) contextual model of disability-social confluence-to the field of music education.

Keywords: disability, music education, wheelchair basketball, medical model, functional ability, impairment, social model, social confluence, (dis)Ability, Patrick Anderson

Before my accident I played sports and music.

After my accident I played sports and music.

(Patrick Anderson, wheelchair basketball athlete, Team Canada)

t the 2012 Paralympic Games in London Patrick Anderson, "the greatest
player in the history of wheelchair basketball" (Labanowich and
Thiboutot 2011, 519), led Team Canada to a gold medal for the third time in his career and shortly thereafter, took a four-year break from international competition to focus on being a musician. He went back to school and earned an undergraduate degree in music, taught himself music production skills at home, and formed a folk duo with his wife in Brooklyn. Since 2012 he has engaged in a steady cycle of writing, recording, and touring-staples of being an independent musician. In both sports and music, Patrick has thrived. ${ }^{1}$ 
As the result of being hit by an intoxicated driver at the age of nine, both of Patrick's legs were amputated below the knee. According to the criteria set out by the Canadian government, Patrick is disabled; ${ }^{2}$ however, in the contexts of music-singing, guitar, bass, piano, songwriting-and sports-wheelchair basketball, the classification disabled is a misnomer. Still, Patrick avers that his being labeled as disabled is at times necessary, in that this categorization provides him with access to services that he requires to survive. ${ }^{3}$ The experience of disability is complex, and Patrick's perspective is helpful to elucidate this phenomenon in the contexts of sports and music. Using Patrick's anecdotal experiences of disability in sports and music as catalysts, I discuss key concepts in Disability Studies including the medical and social models of disability, conventions of disability terminology, disability identity, and the relevance of Lubet's (2010) contextual model of disability-social confluence-to the field of music education. To contextualize this discussion in music education, I begin with a brief overview of how the field of music education has conceptualized the construct of disability.

\section{Profiling Patrick}

Over the past six years, I have developed a friendship with Patrick. I have had the pleasure of watching Patrick play sports and music, and we have had several discussions about his experiencing disability in both contexts. Our conversations became the impetus for this inquiry, as I sought to compare his experiences both as a musician and as an athlete. In an effort to go beyond casual conversations to inform my inquiry, I invited Patrick to participate in two semi-structured interviews over Skype, for a combined total of three hours. Subscribing to the perspective that data is created between the interviewer and interviewee (as opposed to the researcher extracting information from the interviewee), these conversations took the form of "InterViews" (Brinkmann and Kvale 2015).4

What became apparent as we discussed Patrick's involvement in sports and music were the different ways in which disability is conceptualized in these domains. As I initially suspected, the field of music education has much to learn from Patrick's experiences in the world of wheelchair basketball. To be clear from the outset, I am not forwarding that wheelchair basketball, or the Paralympics serve as exemplary models for music education; rather, I wish to share Patrick's 
perspectives, informed by his decades-long experiences of grappling with the complex issues surrounding disability.

Considering this volume's call to push our profession into a post-Butera era that maligns social injustice in music education, 5 a call that is increasingly pressing given the current political climate in the United States and parts of Europe, the field of music education needs the perspectives of those who experience disability in our society (Abramo and Pierce 2013, 21). Patrick's perspective provides insights into the complexities of the experience of disability. His nuanced views of how he has experienced disability in sports and music provide a point of entry into Disability Studies, a field of study that some music education scholars (Abramo 2012, Abramo and Pierce 2013, Dobbs 2012, Parker and Draves 2017, Rathgeber 2016) are now exploring.

\section{Mired in the Medical Model: Music Education and Disability}

The Paralympics subscribes to the medical model to classify athletes. Straus (2011) explains that what constitutes disability in the medical model is contingent on the social construct of normal and its polar opposite, abnormal, ${ }^{6}$ both of which are nineteenth-century intellectual inventions:

The medical model of disability ... depends on a fundamental distinction between the normal and abnormal. The term "normal," along with its cognates (abnormal, norm, normative, normalize), emerged in all of the European languages around 1830. These terms and concepts were brought into being by the new science of statistics, a form of social control in which populations are sorted and evaluated according to various human traits, and normed under the familiar bell-shaped curve, with deviants relegated to the margins. Previously disability had been constructed as monstrosity in opposition to the natural, whereas now disability was to be constructed in accordance with a medical model, that is, as an abnormality defined in opposition to the statistical norm (7).

Music education is mired in the medical model of disability. Compared to other areas of injustice in music education that at times have been addressed in isolation, e.g. class, race, gender, and sexuality, the experience of disability encompasses any and all perceived differences amongst humans and is silenced throughout the preponderance of music education discussions; disability lives in the margins of the margins. For example, Lubet (2010) contends that people in post-secondary music programs act as if disability does not exist:

Bell, Adam Patrick. 2017. (dis)Ability and Music Education: Paralympian Patrick Anderson and the Experience of Disability in Music. Action, Criticism, and Theory for Music Education 16 (3): 108-28. doi:10.22176/act16.3.108 
Schools of music are full of faculty and students with concealed performance injuries and invisible impairments such as depression, learning disabilities, and autistic-spectrum conditions. Academic and professional music folk mostly and understandably insist on protecting their careers by pretending to be ablebodied (135).

Lubet's (2010) critique implies a broad conception of what it means to experience disability in music. He claims that music institutions perpetuate a culture of music making that caters to an idealized body, one that is unspoken but understood. Garland Thomson (1997) refers to this idealized body as the normate: "a very narrowly defined profile that describes only a minority of actual people" (8). Speaking specifically to music performance, Howe (2016) writes, "This normal performance body usually possesses all limbs, with above-average hand and finger size, lung capacity, and strength, among other qualities" (196).

Lubet's (2010) argument is well supported by the history of research in music education on disability. For example, Dobbs (2012) found that the literature from 1990-2011 in Journal of Research in Music Education overwhelmingly subscribed to an ableist "hegemony of normativity ... discursively inscribed throughout the dataset" (18). Our field's marquee periodical aimed at practitioners, Music Educators Journal, is replete with articles in which a dichotomy is assumed between a supposed majority of people with normal performance bodies and others whom have been ascribed various labels such as "special needs" (Adamek 2001, Melago 2014, VanWeelden 2001), "special learners" (Hammel 2004), "students with disabilities" (Lapka 2006), "children with disabilities" (McCord \& Fitzgerald 2006), and "emotional disturbances" (Price Jr. 2012). The focus of these articles is often on students' music literacy skill development or their integration into a large ensemble such as band or choir. The field of music education presumes that all students should fit into these existing social structures; if a learner is a misfit, the music educator's role is to solve the problem.

Hence, the field of music education has continually engaged in what Ian Hacking (2007) refers to as "making up people":

We think of these kinds of people as given, as definite classes defined by definite properties. As we get to know more about these properties, we will be able to control, to help, to change, or to emulate them better. But it is not quite like that. They are moving targets because our investigations interact with the targets themselves, and change them. And since they are changed, they are not quite the same kind of people as before. The target has moved. That is the

Bell, Adam Patrick. 2017. (dis)Ability and Music Education: Paralympian Patrick Anderson and the Experience of Disability in Music. Action, Criticism, and Theory for Music Education 16 (3): 108-28. doi:10.22176/act16.3.108 
looping effect. Sometimes our sciences create kinds of people that in a certain sense did not exist before. That is making up people (293). ${ }^{7}$

The role of the music educator in a teaching and learning context fits Hacking's description of the "professional" in the looping effect of making people:

$[P]$ rofessionals ... generate or legitimate the knowledge, judge its validity, and use it in their practice. They work within institutions that guarantee their legitimacy, authenticity, and status as experts. They study, try to help, or advise on the control, of the people who are classified as of a given kind (italics added for emphasis, 297).

In other words, music educators play a pivotal role in making music learners disabled. For example, McCord and Fitzgerald (2006) provide a comprehensive list of instrument suggestions for students with various visible and invisible impairments, including: "A sousaphone with sousaphone chair holder can help students with ADHD or emotional and behavioral disabilities that make it difficult for them to focus and remain in one place for an extended period of time" (48). This example implies that the combined mass and design of the instrument serves to restrain the student from moving. The problem encountered in this situation is attributed solely to the student's inability to sit still and "focus." This example demonstrates music education's propensity to conceptualize disability as an individual deficit that must be repaired. ${ }^{8}$ Such thinking is underpinned by ascribing to the binary of dis/ability: both in research and practice, music educators demarcate the able from disabled, sorting learners into separate spurious categories that deny the dynamic fluidity of the body. Referencing Stephen Garton's (2000) research on the influence of eugenics (hereditary, social, racial, psychological, and familial factors) on widespread classifying practices in education during the twentieth century, Bernadette Baker (2002) observes: "The production of and hunt for different forms of disability ... that circulate at the turn of the 21st century often pay homage to similar lists of factors" (672-3).

I maintain that music education must focus on moving toward conceptualizing disability as an experience rather than a fixed individual deficit. Thus, music educators need to consider the socio-cultural norms of the musicmaking cultures in which teachers and learners dwell, and examine if and how they contribute to individuals' experiences of disability in music.

Bell, Adam Patrick. 2017. (dis)Ability and Music Education: Paralympian Patrick Anderson and the Experience of Disability in Music. Action, Criticism, and Theory for Music Education 16 (3): 108-28. doi:10.22176/act16.3.108 


\section{Conceptualizing "Disability" in Wheelchair Basketball and Its Implications for Music Education}

Patrick's reflections on playing sports and music provide ways of thinking about the experience of disability that could be helpful to music educators. Stras (2016) observes: "Since antiquity, parallels have been drawn between music and sport, which are often critiqued using similar aesthetic and moral frameworks. In both, humans negotiate issues of virtuosity, competition, teamwork, talent, grace, inspiration, and elitism" (176-7). As Patrick and I began our conversations, we examined the construct of disability in the context of Paralympic sports.

Adam: It seems to me that in sports, there are much more developed and complex systems. You know, you're a professional athlete. In music, it seems to me that there aren't really things in place and maybe that's because they aren't needed, but I just found it interesting that there is this whole Paralympic structure. I remember you telling me about the points system...

Patrick: Yep, classification system.

Adam: Based on the degree of "impairment"?

Patrick: "Functional ability"? So, the greater the functional ability, the greater the point value. The higher the classification, the higher your functional ability. As opposed to saying, "This guy is more disabled."

Adam: And that's another interesting thing. The language on the website for Paralympics, they use the term "impairment." In some of the books I've been reading, they [authors] make a distinction between impairment and ability and/or disability. Can you weigh in on any of that kind of language used?

Patrick: You know, there are parallels in race and gender and what not, that it's certainly a moving target. Sometimes culturally, it seems like handicapped is used more down here [in the United States] still. But I think it's a little bit of a hang-up. You can't just replace all of the signage overnight. There's a lot of handicap parking, but I imagine in twenty years it's not going to be there anymore because there's a bit of a stigma attached to that term now. Disabled is still kind of ok, but some people get into putting the person first, so athlete with a disability or person with a disability. Some people find that stuff important. That's as much as I would say about it. There's that whole: black people calling themselves the N-word. There's a bit of that. We can refer to each other as cripples on the court, or in the subculture. But you'd have to be an in-member to use that. It doesn't mean you can call me a cripple. Because I call a teammate, "That was a really cripple move," when he bounced the ball off his face or whatever. I mean, there's a bit of that present.

Adam: Is that something that is pretty common in wheelchair basketball?

Patrick: Yeah, I would say it's very common, but there's the nuance or the wrinkle that is maybe different than say, with race-not everyone is equally disabled or has functional abilities. For me to direct a comment like that towards fellow amputees, so someone who's the same as me, is kind of fine. But

Bell, Adam Patrick. 2017. (dis)Ability and Music Education: Paralympian Patrick Anderson and the Experience of Disability in Music. Action, Criticism, and Theory for Music Education 16 (3): 108-28. doi:10.22176/act16.3.108 
to direct a comment like that towards a high paraplegic, someone who has less functional ability, who is more disabled, could come across as more demeaning. Like, "You suck because you're disabled," because he really is more disabled than me, versus, "You suck because you're disabled, and I'm disabled too in the exact same way, so I don't really mean it, I'm just teasing you." You have to be more careful around disability because it's like gender. It's certainly not binary like disabled or not.

\section{A Rationale for the Medical Model of Disability}

Patrick makes a number of critical points in need of further explication. The first key point relates to why wheelchair basketball subscribes to a medical model of classifying disabilities. Some explanation of how wheelchair basketball is organized is necessary to understand the context of this discussion on what disability means in the wheelchair basketball community. Wheelchair basketball is its own distinct sport; it would be erroneous to conceive of it as "basketball in wheelchairs" because it was created for a particular group of athletes. Terms such as functional ability, impairment, or disability refer to individuals' bodily traits. Participants are classified on a scale of 1 to 4.5 in increments of 0.5 , with higher ratings corresponding with higher functional abilities and vice versa; no team is permitted to have more than 14 points on the floor at any one time (Labanowich and Thiboutot 2011, 202). By classifying functional abilities in wheelchair basketball, the presumption is that an even playing field is established:

Challenging the interests of para-sport is the threat of one sided and predictable competition, in which the least impaired athlete always wins. To prevent this, para-athletes are placed in categories for competition based on their impairment; these are called sport classes (International Paralympic Committee 2017).

Similar logic is employed in the classification systems of sports such as boxing and judo that factor in age, weight, or height (Ellis 2015, 125). The classification system allows Patrick to easily compare himself to other athletes and gauge the supposed competitive advantage one athlete is thought to have over another. Within the sport of wheelchair basketball, the idea of one athlete being more able than another is made explicitly clear to all competitors, understandably so because of the implications for the athletes, their teammates, and their competitors.

In music education, a line is drawn between the so-called able and disabled, and further categorizations are made within these separate spheres (e.g. severely

Bell, Adam Patrick. 2017. (dis)Ability and Music Education: Paralympian Patrick Anderson and the Experience of Disability in Music. Action, Criticism, and Theory for Music Education 16 (3): 108-28. doi:10.22176/act16.3.108 
disabled, developmentally delayed, gifted, etc.); in wheelchair basketball, a ranking system is used with the aim of producing a competitive environment deemed fair by the governing organizations of the sport. While both systems are problematic in that they further discriminate the discriminated, commendably, the focus within the Paralympics is on what the athlete is able to do (functional ability); by comparison, music education tends to dwell on what the learner is unable to do.

\section{Disability Terminology}

The second key point Patrick makes is in regard to the language used to discuss the construct of disability. From Patrick's perspective, terminology is "a moving target." He observes that "handicapped" is used more in the United States than in Canada, and adds: "Disabled is still kind of ok, but some people get into putting the person first, so athlete with a disability or person with a disability." Pullin (2009) begins his book, Design Meets Disability, with the statement: "Any language used to describe the issues around disability is understandably-and rightly-politically charged" (1). His discussion on nomenclature in disability studies captures the complexity and nuances inherent in the language used to talk about the construct of disability in society. The medical model utilizes a simple logic: a disability is a trait, and therefore an individual can be classified as disabled or not on these grounds. In contrast, the social model challenges this perspective with two humanistic schools of thought on contextualizing the descriptor "disability" in relation to human beings. The first approach within the social model is to label a person as disabled. The intention of this terminology is to suggest that a person is disabled due to their environment, not by their impairment. The person is disabled because their differences are disadvantaged by the predominant norms and values of society. The other approach, which is especially more common in North America, is to employ people-first language, labeling a person as someone with a disability. The intent of people-first language is to avoid having people's impairments be intertwined with their social identities because a disability is something that you have, not something that you are. 9 Essentially, both approaches argue for the same end from different perspectives, and typically, which approach is more appropriate is dependent on the social context of a particular community. ${ }^{10}$

Bell, Adam Patrick. 2017. (dis)Ability and Music Education: Paralympian Patrick Anderson and the Experience of Disability in Music. Action, Criticism, and Theory for Music Education 16 (3): 108-28. doi:10.22176/act16.3.108 


\section{Disability as Identity}

The third key point that Patrick made is that in wheelchair basketball, disability can be a socially-bonding identity: "We can refer to each other as cripples on the court, or in the subculture. But you'd have to be an in-member to use that." In part, this can be explained by the history of the sport. Initially intended for WWII veterans with disabilities, the Paralympics were founded in 1948 by Sir Ludwig Guttmann, who claimed: "The Second World War, with its large number of disabled, provided a new and great incentive for reviving the idea of sport as an aid to the treatment and rehabilitation of war disabled" (Guttmann 1976, 17). What was originally conceived of as a modality of rehabilitation has since morphed into a worldwide competitive organization reserved solely for disabled athletes. Since their inception, organized Paralympic sporting events have gradually garnered a broader appeal (e.g. 2.7 million tickets were sold to events at the London games in 2012, and 2.15 million tickets were sold to events at the Rio games in 2016).

Paralympic sports create new social contexts in which the norms governing what constitutes a disability are upended to the extent that they become advantageous. Whereas using a wheelchair is typically perceived as an impediment to mobility in urban environments due to a lack of navigable infrastructure (e.g. ramps and elevators), in contrast, being in a wheelchair is a prerequisite of several Paralympic sports, relegating the so-called able-bodied athlete in this scenario as disabled. How an athlete is categorized on either side of the ability/disability dichotomy is contingent on the context of the event. The Paralympic movement has purposely adhered to criterion-based definitions of impairment ("functional ability") to construct a distinct category of athlete. This conscious form of self-exclusion has served in a roundabout way to achieve social inclusion as these events have come to be accepted as part of the panoply of spectator sports as entertainment. This is the Paralympic paradox, a case where the means are exclusion and the ends are inclusion, albeit inclusion within a specific context. Self-segregating as "disabled" and subsequently delineating degrees of disability-a seemingly contradictory coalescence of dichotomous and continuous categorization models employed by the Paralympics-works because participants choose to identify as disabled. In countries with smaller populations (such as Canada, where Patrick is from), able-bodied players are permitted to

Bell, Adam Patrick. 2017. (dis)Ability and Music Education: Paralympian Patrick Anderson and the Experience of Disability in Music. Action, Criticism, and Theory for Music Education 16 (3): 108-28. doi:10.22176/act16.3.108 
play wheelchair basketball. Patrick explained that for some disabled players, this is regarded as a form of social trespassing:

There's an amputee on my team who said, "When I found wheelchair basketball, it was like this thing that I had that able-bodied people didn't have access to." That was part of the draw for him. We're talking about this in the context of able-bodied involvement. Even though he has nothing to fear from them talent or functional-wise, he's an amputee like me, he could totally compete against able-bodied players, but psychologically there was a "This is a safe place for me, or something that I lost in losing my leg, I got it back here and I don't want to lose that, I want to safeguard it."

For some individuals, identifying as disabled or having a disability is paramount, and therefore this paralympic paradigm can be transferred to the world outside of sports. Parallels of this phenomenon in music include the rock bands Pertti Kurikan Nimipäivät (profiled in the 2012 documentary The Punk Syndrome) and The AutistiX, as well as the Paraorchestra:

The orchestra was begun by conductor Charles Hazlewood, and was launched ... with eighteen members. Their disabilities include severe motor impairment, learning differences, and hearing and sight impairments: they were assembled on the basis of their musicianship, not the fit of their instruments to a predetermined array, so the ensemble comprises "normal" orchestral woodwind and string instruments, as well as piano, recorder, harp, sitar, and oud. Some members only have access to music performance through electronic technology: the trumpeter Clarence Adoo, who has no mobility below his neck, plays an instrument called Headspace, which he activates by blowing down a tube. Composer Lyn Lovett, who has severe cerebral palsy, triggers musical events on an iPad with her nose (Stras 2016, 186).

In an educational climate in which inclusion is championed as the ethical solution to dissolve the ability/disability division, endorsing exclusion may understandably seem close-minded, undemocratic, and in support of further marginalizing disenfranchised populations in our society. I am not promoting disability segregation in music education, but there may be instances in which learners choose to organize around an identity of disability. Parallels exist in other domains of identity such as the all-African-American Orchestra Noir: "Orchestra Noir raises 'the invisible curtain' and brings classical music to diverse, younger audiences that is relevant and respectful of their community" (Orchestra Noir 2017). The New York City Gay Men's Chorus sings "to challenge perceptions of the LGBTQ community, to combat fear and hatred, encourage compassion and human connection, and to thrill with the superb quality of our sound" (New York City Gay Men's Chorus 2017). These are but a few examples of how music can

Bell, Adam Patrick. 2017. (dis)Ability and Music Education: Paralympian Patrick Anderson and the Experience of Disability in Music. Action, Criticism, and Theory for Music Education 16 (3): 108-28. doi:10.22176/act16.3.108 
serve as an identity beacon for marginalized populations. Following along similar lines, when an individual or a group manifests a disability identity in a musicmaking context, the music educator should recognize and support it.

\section{(dis)Ability: Toward Social Confluence}

Patrick: In my experience, I definitely gravitated towards organized disabled sport and at the same time, any time I was faced with any kind of organized disabled music-and it wasn't very often-it was the opposite reaction.

For me, that's where I needed to go to play basketball because I needed to find other people in wheelchairs. It was more a matter of necessity and then later on when I started to realize that other people didn't need to have a disability to get into a chair and play, that kind of opened my eyes to the fact that I didn't necessarily need disabled players to play wheelchair basketball, to be a wheelchair athlete.

I really like the idea of open points where able-bodied and disabled players compete on an equal playing field, because I think it's less like, "Well, why can't you be as good as Pat, you're missing two legs and he's missing two legs." It's more like, "Well, you can't be as good as him because he's a great athlete out there competing with other great athletes." To me, it breaks this direct lineage between, "You have 'disability x' and you have 'disability x," or maybe just disability period. It puts the emphasis on, "Oh, the best ten basketball players are on the court, and if you can get to that level, it's because you're a great athlete." It's not because you're disabled and you have this secret pipeline or something. We're going to develop something where you guys (able-bodied athletes) are the center of it, not the peripheral. And disabled [athletes], if they fit and they measure up, then they can play. I just wanted to flip the script.

The significance of Patrick's advocacy for an open points system in wheelchair basketball indicates a radical departure from the traditional medical (functional ability) model of disability. By suggesting that able-bodied athletes constitute the core of wheelchair basketball, Patrick is questioning the sociocultural context of disability in sport. This way of thinking is congruent with the social model of disability:

Disability Studies understands disability not as a mark of divine disfavor or inspiration nor as a medical pathology but rather as a social and cultural construction. Within this new social model, disability is understood as an aspect of the diversity of human morphology, capability, and behavior: a difference, not a deficit (Straus 2011, 9).

Contending that the experience of disability "emerges from a society that chooses to accommodate some bodies and exclude others" (Howe et al. 2016, 2), Disability Studies scholars differentiate impairment-“an underlying biological

Bell, Adam Patrick. 2017. (dis)Ability and Music Education: Paralympian Patrick Anderson and the Experience of Disability in Music. Action, Criticism, and Theory for Music Education 16 (3): 108-28. doi:10.22176/act16.3.108 
or medical condition" (Straus 2011, 4)-from disability-"the meanings conferred on impairment by social and cultural construction" (4). Often pitted as polar opposites, both the social model and medical model have been critiqued by some Disability Studies scholars for being too extreme. Anderberg (2005) summarizes these shortcomings:

The medical model oversimplifies disability as an individual characteristic and directs attention towards individual adjustments and means. The social model, on the other hand, directs attention towards ideological and political analysis, not towards practical everyday solutions for experienced functioning. (n.p.)

The medical model reinforces a simple dichotomous system of able/disabled based on diagnostic data, and the outgrowth of this practice is the presumptive thinking that perpetuates the bifurcation of ability/disability without critical regard to context. But devotion to the opposite-the social model-is not without its faults, as rigid adherence to explaining disability as a social phenomenon can prove problematic, too. For example, a person may experience emotional or physical problems that cannot be attributed to a society's (mis)treatment. Further, how an individual or group of people experience "disability" or "impairment" can vary (Barnes and Mercer 2003). Consider, for example, the phenomenon of pain: it can stem from factors unrelated to society and can be experienced differently by different people.

Patrick navigates these different models of disability fluidly, and oftentimes he has no choice in the matter on how his impairment is regarded. For example, to determine whether or not he was eligible for New York City Access-a-Ride, he had to take a test of sorts at a simulated bus stop evaluated by public officials. He recalled, "There were three options to get on this fake bus: stairs, lift, and ramp. I must have technically failed, because I jumped out of my chair and carried it up the stairs. But I think it was a formality once they saw that I was a double amputee-I was in." Getting an accessible parking permit also requires proof: "For disabled parking passes, there's a state pass and a NYC pass. For the state pass, you need a doctor's signature. For the city pass, it's a little more rigorous ... not only the signature, but some documentation (i.e. x-rays) to prove that you're really disabled." In these scenarios, to receive basic necessities, Patrick has to accept a medical definition of disability. ${ }^{11}$

Bell, Adam Patrick. 2017. (dis)Ability and Music Education: Paralympian Patrick Anderson and the Experience of Disability in Music. Action, Criticism, and Theory for Music Education 16 (3): 108-28. doi:10.22176/act16.3.108 


\section{Social Confluence and Music}

Patrick: ...but with music, that's not the case. I could pick up the guitar and play with anybody. That's not to say that I haven't hit different sorts of roadblocks, but my response has either been, "I'll do something else," or take piano [for example], like a pedal, I don't pedal. That's how I mastered the art of connecting notes without it (the sustain pedal). It's called crawling, which is connecting [notes], because you don't have sustain, so connecting notes, in other words, your hand movement is different than playing piano. So that's kind of how I play piano. That's one response, the other response would be to go get an adaptive e-pedal made.

There are [other] small things like guitar pedals and things like that. People feel [the pedals] at the mic while they're playing, they're not even looking, they're feeling with their toes. I couldn't do that. I don't have that kind of control, so I'm just going to leave that whole area off to the side and do other things. And in music there are a million things that you can do and ways of approaching things, so it doesn't seem like I hit dead ends, I just hit forks.

Of the few times that I've come across disability and music things, in one case I was very turned off. That was this Vancouver Adapted Music Society and I think part of it grew out of the dawning and growing of my self-awareness as an athlete, the limits of defining myself as a disabled athlete, and the frustrations of sort of hitting this glass ceiling with disabled athletes and not being able to compete against even better athletes whether they be disabled or not disabled. So I didn't want to confine myself to the same kind of limited talent poolespecially in music, where it's not necessary, particularly not necessary. Whatever it is, whether it's a solidarity thing or a marketing thing, whatever, they put out an album every once in a while. A friend of mine was involved in it, and I just said, "I want nothing to do with 'disabled music night' or 'disabled music society album' or anything like that."

On the other hand, [at the] 2004 Paralympics, the organizing committee flew in some Canadian [musicians for] this showcase. There's always an event before [the] Games start where the whole Canadian delegation gets together for a welcome pep rally kind of thing. They had this concert and it was unbelievable. A few of the acts were ok, but two of the acts were amazing. One of them was this single amputee violinist (Adrian Anantawan) who's at Julliard or some comparable school in the US. ${ }^{12}$ The other guy was the lead singer of Bass is Base (Chin Injeti) he has polio. ${ }^{13} \mathrm{He}$ was there and he played guitar and sang. In that context, it's totally cool. I'm glad they're going with these (sports and music) together, [themed] around disability.

How Patrick thinks about and navigates the experience of disability in music depends on context. Lubet (2010) contends the experience of disability as everchanging from situation to situation can be explained by his theory of social confluence, which "states that modern society does not consist of stable, intact units of identity known as individual human beings, but rather of people whose identities morph constantly with changing circumstances or contexts” (10).

Bell, Adam Patrick. 2017. (dis)Ability and Music Education: Paralympian Patrick Anderson and the Experience of Disability in Music. Action, Criticism, and Theory for Music Education 16 (3): 108-28. doi:10.22176/act16.3.108 
Patrick does not experience disability when he sings and plays guitar, which might explain why he has been reluctant to join a music organization where disability is a central part of its identity. He may need to be labeled as disabled to get to a gig but once in the gig, he sheds that identity. Because New York City's subway system is mostly inaccessible to Patrick, he drives to the music venues where he performs, and he depends on accessible parking. A special permit is required to use accessible parking spots, and therefore Patrick needs to be identified as disabled for this purpose. In the venue, on stage playing guitar and singing, Patrick does not experience disability, and therefore he does not have a need to identify as disabled for this purpose.

Still, Patrick does experience disability in music, such as the challenges posed by not being able to depress a sustain pedal on a piano or use guitar pedals, at least in the conventional sense. His realization that "in music there are a million things that you can do and ways of approaching things, so it doesn't seem like I hit dead ends, I just hit forks," should serve as guiding words for music educators. Instrument adaptation has a strong tradition in the field of music therapy (Bell 2017), and there are promising possibilities for music education in making bespoke instruments for people who do not fit the mold of the normal performance body as evidenced by the work of Drake Music Lab in London and the Monthly Music Hackathon in New York City; ${ }^{14}$ however, music education might also benefit, as Patrick's reflection implies, from exploring alternative possibilities. Rather than trying to make an instrument fit a person or vice versa, it may be more prudent to simply try something different musically.

In discussing two different contexts in which music was enmeshed with a disability identity, Patrick presented two different reactions. In response to an invitation to participate in Vancouver Adapted Music Society, Patrick responded: "I want nothing to do with 'disabled music night' or 'disabled music society album' or anything like that." In contrast, reflecting on a 2004 Paralympics "pep rally" that featured musicians with impairments, Patrick commented: "In that context, it's totally cool. I'm glad they're going with these (sports and music) together, [themed] around disability." As is often the case, context is critical for understanding the phenomenon. Disability depends.

For the field of music education, dwelling on (dis)Ability may be a helpful way to think about social confluence on a day-to-day basis. The dis is bracketed to acknowledge that the experience of disability in music is an ever-present the Experience of Disability in Music. Action, Criticism, and Theory for Music Education 16 (3): 108-28. doi:10.22176/act16.3.108 
possibility; however, the focus of the music educator ought to be on fostering the experience of ability in music. When individuals experience disability in the music-learning context, pedagogy must be questioned.

\section{The Panda and the Wheelchair: Conclusions}

The World Wildlife Fund uses a Giant Panda as its symbol for endangered species conservation; it represents the earth's estimated 5 to 15 million species of plants, animals, and micro-organisms. How the human species cares for the Giant Panda is indicative of how it treats the planet. Similarly, the wheelchair is the global symbol for disability, officially known as the International Symbol of Access (Hendren 2016). This symbol is placed on public bathrooms, parking spaces, and automatic doors, all to indicate these spaces are accessible for people with disabilities. As a result of this practice, the wheelchair and disability are synonymous in society, and it represents all disabilities. The wheelchair represents just the tip of the disability iceberg in society, let alone music education. Pedagogical approaches for those who experience disability in music education are indicative of the health of the field. Representation of diversity and difference in music education is a manifestation of attempts to thwart institutional injustice, but more often than not this remains an ideal. Lubet (2010) observes:

It is disturbing because those people of color and people with disabilities who perceive the standard curriculum as ignorant, apathetic, oblivious, or even hostile to their interests are simply absent. Thus, cultural inequities manifest themselves as exclusion (139).

The field of music education errs by presuming that the absence of people with impairments in classrooms and community contexts is representative of reality. Learners who do not fit the mold of the idealized normal performance body are expected to conform to the ableist social structures of music programs, or else risk being ostracized. Citing the "World Report on Disability" from 2011, Goodley (2014) notes, "15 per cent of the world's population live with an impairment" (14). In short, the experience of disability is a widespread global phenomenon to which music education is not exempt. Furthermore, by our own societal standards of what constitutes disability, anyone who lives long enough will eventually become disabled in music. For example, the effects of ageing on bones, muscles, and joints results in reduced strength and flexibility; the

Bell, Adam Patrick. 2017. (dis)Ability and Music Education: Paralympian Patrick Anderson and the Experience of Disability in Music. Action, Criticism, and Theory for Music Education 16 (3): 108-28. doi:10.22176/act16.3.108 
idealized normal performance body is ephemeral. The periodical, Medical Problems of Performing Artists, exists solely to address the toll that music takes on our bodies. For a field that prides itself on lifelong learning, a more complex way of conceptualizing disability is needed for this ideal to become a reality.

Garnered through my experiences in both practice and research, I have developed an overtly strong bias in favor of the social model to understand and explain the construct of disability in music. One of my foremost fears as a music educator is that my pedagogy causes or contributes to someone's experience of disability in music. To guard against this I must continually examine the culture I foster in the music-learning realm, and ask myself: "How, when, and where do I contribute to a fellow human's experience of disability in music?” My mentality is grounded in a simple maxim, one that posits that music-making experiences ought to be accessible to all. While I suspect that most, if not all, music educators would agree with this statement, the relative dearth of attention to Disability Studies in music education reflects a troubling reality: on the whole, the field has thus far failed to grapple with the construct of disability and its associated effects of marginalization. The primary benefit that Disability Studies offers music educators is how to think about disability, which might influence how researchers examine existing pedagogical approaches and invent and enact new ones. "How-to" inclusive and/or universal strategies outlined in articles aimed at teachers are useful in many music education contexts, but they require a critical and theoretical consideration of the specific scenarios in which they are to be used. Disability Studies provides a framework with which to contemplate the multiple aspects and consequences of these actions. Specifically, Lubet's (2010) conception of social confluence, which foregrounds context, can help us to escape the trap of thinking about disability as a fixed state. To this end, (dis)Ability serves as a tool to focus on ability, to be mindful that the experience of disability is an ever-present potential in music education. Alertness to (dis)Ability makes experiences of disability in music the social responsibility of a collective of music makers. When we think and act in this way, sousaphones are no longer perceived as anchors, but as buoys.

Bell, Adam Patrick. 2017. (dis)Ability and Music Education: Paralympian Patrick Anderson and the Experience of Disability in Music. Action, Criticism, and Theory for Music Education 16 (3): 108-28. doi:10.22176/act16.3.108 


\section{About the Author}

Adam Patrick Bell is an Assistant Professor of Music Education in the School of Creative and Performing Arts at the University of Calgary, Canada. He is the author of Dawn of the DAW: The Studio as Musical Instrument (Oxford University Press, 2018), and has written several peer-reviewed articles and chapters on the topics of music technology in music education, and disability in music education. Prior to his career in higher education, Bell worked as a kindergarten teacher, elementary music teacher, and support worker for adolescents with disabilities. Bell has also worked as a freelance producer, creating commercial music for clients including Coca-Cola.

\section{References}

Abramo, Joseph. 2012. Disability in the classroom: Current trends and impacts on music education. Music Educators Journal 99 (1): 39-45.

Abramo, Joesph Michael, and Amy Elizabeth Pierce. 2013. An ethnographic case study of music learning at a school for the blind. Bulletin of the Council for Research in Music Education 195: 9-24.

Adamek, Mary S. 2001. Meeting special needs in music class. Music Educators Journal 87 (4): 23-6.

Amundson, Ron. 2000. Against normal function. Studies in History and Philosophy of Biological and Biomedical Sciences 31 (1): 33-53.

Anderberg, Peter. 2005. Making both ends meet. Disabilities Studies Quarterly 25 (3). http://dsq-sds.org/article/view/585/762

Baker, Bernadette. 2002. The hunt for disability: The new eugenics and the normalization of school children. Teachers College Record 104 (4): 663-703.

Barnes, Colin, and Geof Mercer. 2003. Disability. Cambridge, UK: Polity Press.

Bell, Adam P. 2008. The heart of the matter. International Journal of Education and the Arts 9 (9). http://www.ijea.org/v9n9/index.html

Bell, Adam P. 2017. Music therapy. In The Routledge companion to music, technology, and education, edited by Andrew King, Evangelos Himonides, and S. Alex Ruthmann, 347-56. New York and London: Routledge.

Brinkmann, Svend, and Steinar Kvale. 2015. InterViews: Learning the craft of qualitative research interviewing. Thousand Oaks, CA: Sage.

Bell, Adam Patrick. 2017. (dis)Ability and Music Education: Paralympian Patrick Anderson and the Experience of Disability in Music. Action, Criticism, and Theory for Music Education 16 (3): 108-28. doi:10.22176/act16.3.108 
Dobbs, Teryl L. 2012. A critical analysis of disabilities discourse in the Journal of Research and Music Education, 1990-2011. Bulletin of the Council for Research in Music Education 194: 7-30.

Ellis, Katie. 2015. Disability and popular culture: Focusing passion, creating community, and expressing defiance. Farnham, UK: Ashgate.

Garland Thomson, Rosemarie. 1997. Extraordinary bodies: Figuring physical disability in American culture and literature. New York: Columbia University Press.

Garton, Stephen. 2000. Writing eugenics: A history of classifying practices. In " $A$ race for place": Eugenics, Darwinism, and social thought and practice in Australia, edited by Martin Crotty, John Germov, and Grant Rodwell, 9-18. Newcastle, AU: University of Newcastle Press.

Goodley, Dan. 2014. Dis/ability studies: Theorising disablism and ableism. London and New York: Routledge.

Guttman, Sir Ludwig. 1976. Textbook of sport for the disabled. Aylesbury, UK: $\mathrm{HM}+\mathrm{M}$.

Hacking, Ian. 2007. Kind of people: Moving targets. Proceedings of the British Academy 155: 285-318.

Hammel, Alice M. 2004. Inclusion strategies that work. Music Educators Journal 90 (5): 33-7.

Hendren, Sara. 2016. An icon is a verb. http://accessibleicon.org/

Hocutt, Anne M., and Joni Y. Alberg. 1994. Case studies of the application of categorical and noncategorical special education. Exceptionality: A special education journal 5 (4): 199-221.

Howe, Blake. 2016. Disabling music performance. In The Oxford handbook of music and disability studies, edited by Blake Howe, Stephanie JensenMoulton, Neil Lerner, and Joseph Straus, 191-209. New York: Oxford University Press.

Howe, Blake, Stephanie Jensen-Moulton, Neil Lerner, and Joseph Straus. 2016. Introduction: Disability studies in music, music in disability studies. In The Oxford handbook of music and disability studies, edited by Blake Howe, Stephanie Jensen-Moulton, Neil Lerner, and Joseph Straus, 1-11. New York: Oxford University Press.

Bell, Adam Patrick. 2017. (dis)Ability and Music Education: Paralympian Patrick Anderson and the Experience of Disability in Music. Action, Criticism, and Theory for Music Education 16 (3): 108-28. doi:10.22176/act16.3.108 
International Paralympic Committee. 2017. Classification introduction. https://www.paralympic.org/classification

Labanowich, Stan, and Armand "Tip" Thiboutot. 2011. Wheelchairs can jump! A history of wheelchair basketball. Boston, MA: Acanthus.

Lapka, Christine. 2006. Students with disabilities in a high school band: "We Can Do It!” Music Educators Journal 92 (4): 54-9.

Lubet, Alex. 2010. Music, disability, and society. Philadelphia: Temple University Press.

McCord, Kimberly, and Margaret Fitzgerald. 2006. Children with disabilities playing musical instruments. Music Educators Journal 92 (4): 46-52.

Melago, Kathleen A. 2014. Strategies for successfully teaching students with ADD or ADHD in instrumental lessons. Music Educators Journal 101 (2): 37-43.

New York City Gay Men's Chorus. 2017. Who we are. http://www.nycgmc.org/ who-we-are/

Orchestra Noir. 2017. About us. http://www.orchestranoir.com/about.html

Parker, Elizabeth Cassidy, and Tami J. Draves. 2017. A narrative of two preservice music teachers with visual impairments. Journal of Research in Music Education 64 (4): 385-404.

Price Jr., Brian S. 2012. Zero margin for error: Effective strategies for teaching music to students with emotional disturbances. Music Educators Journal 99 (1): 67-72.

Pullin, Graham. 2009. Disability meets design. Cambridge, MA: The MIT Press.

Rathgeber, Jesse. 2016. A place in the band: Negotiating barriers to inclusion in a rock band setting. In The Routledge research companion to popular music education, edited by Gareth Dylan Smith, Matt Brennan, Phil Kirkman, Zack Moir, and Shara Rambarran, 369-81. London: Routledge.

Stras, Laurie. 2016. Subhuman or superhuman? (Musical) assistive technology, performance enhancement, and the aesthetic/moral debate. In The Oxford handbook of music and disability studies, edited by Blake Howe, Stephanie Jensen-Moulton, Neil Lerner, and Joseph Straus, 176-90. New York: Oxford University Press.

Bell, Adam Patrick. 2017. (dis)Ability and Music Education: Paralympian Patrick Anderson and the Experience of Disability in Music. Action, Criticism, and Theory for Music Education 16 (3): 108-28. doi:10.22176/act16.3.108 
Straus, Joseph N. 2011. Extraordinary measures: Disability in music. New York: Oxford University Press.

VanWeelden, Kimberly. 2001. Choral mainstreaming: Tips for success. Music Educators Journal 88 (3): 55-60.

\section{Notes}

${ }^{1}$ Patrick playing wheelchair basketball: https://www.youtube.com/watch?v=gq K2grrMDQs; playing music: https://www.youtube.com/watch?v=JfE6XbyeFNM

2 According to the website of the Canadian federal government, "a disability must be both 'severe' and 'prolonged,' and it must prevent you from being able to work at any job on a regular basis. Severe means that you have a mental or physical disability that regularly stops you from doing any type of substantially gainful work. Prolonged means that your disability is long-term and of indefinite duration or is likely to result in death." These criteria are assessed by medical adjudicators. https://www.canada.ca/en/services/benefits/publicpensions/cpp/ cpp-disability-benefit.html\#disability

3 In the United States, “(a) Use of categories helped generate advocacy and consequently Congressional support for the legislation, (b) use of the categories helped Congress and the public understand who was meant to benefit from the legislation (i.e. children with disabilities) and who was not to benefit (i.e. poor or underachieving children), and (c) proponents of the law feared that if a noncategorical approach were employed, the resulting debate would detract from the primary mission of ensuring a free, appropriate public education for all handicapped students.” (Hocutt and Alberg 1994, 200)

4 Patrick consented to participating in the interviews knowing they would be recorded and transcribed. Furthermore, Patrick read the article prior to being submitted for review and approved of the accuracy of the excerpted quotes.

5 Excerpt from the Call for Papers: Background: In 2014, the College Music Society published a report from its Task Force on the Undergraduate Music Major (the report some have called a "manifesto") which called for sweeping changes in university-level music curricula (including music education) intended to create more diversity among students and faculty, and within curricula. The report, however, did not investigate the issues underlying the perceived need for change. In April 2016, at a meeting of the National Endowment for the Arts, NAfME's designated representative, Michael Butera, drew attention to institutional racism and the under-representation of people of color in music education through his unfortunate comment that "Blacks and Latinos lack the keyboard skills needed for this field." The opportunity to explore these important issues was lost when Mr. Butera abruptly left the meeting, precipitating a

Bell, Adam Patrick. 2017. (dis)Ability and Music Education: Paralympian Patrick Anderson and the Experience of Disability in Music. Action, Criticism, and Theory for Music Education 16 (3): 108-28. doi:10.22176/act16.3.108 
firestorm on social media. Beneath both the NAfME controversy and the CMS Task Force report lie significant challenges to a discipline fond of claiming that "music is for everyone." Because music education does not appear to be for everyone, at least under present circumstances, careful and considerate exploration of the underlying reasons is a matter of urgency for the profession.

${ }^{6}$ This point is also well-articulated by Amundson 2000.

7 Describing the processes that "drive both the knowledge and the making up of people," Hacking outlines ten "engines of discovery": counting, quantifying, creating norms, correlating, medicalizing, biologizing, geneticizing, normalizing, bureaucratizing, and lastly, resisting (to these aforementioned processes by those striving to reclaim their identity) (310-11).

8 In my earlier work as a graduate student (Bell 2008), I made the same flawed presumption.

9 See Dobbs (2012) regarding the problematics of person-first language within disability studies regarding identity and politics.

${ }^{10}$ Throughout this article I have used these approaches interchangeably, and my word choices are the result of subjective decisions. I made these decisions with the belief that some phrasings better communicate than others my intention: to emphasize that what is perceived as a disability is a byproduct of the construct of normalcy within a society. Abramo (2012) made an important contribution to the practitioner community in music education by explaining these conventions of language and stressing their criticality in changing the culture around disability in the field.

${ }^{11}$ See note 2 and 3.

12 Anantawan studied at the Curtis Institute of Music in Philadelphia, Yale University, and the Harvard Graduate School of Education.

${ }^{13}$ Injeti is part of a music production group called the New Royales and has worked with artists such as Eminem and Drake.

14 Drake Music Lab (drakemusic.org) and Monthly Music Hackathon NYC (monthlymusichackathon.org) both host events in which existing instruments are adapted or new instruments are created for people with disabilities.

Bell, Adam Patrick. 2017. (dis)Ability and Music Education: Paralympian Patrick Anderson and the Experience of Disability in Music. Action, Criticism, and Theory for Music Education 16 (3): 108-28. doi:10.22176/act16.3.108 